In this article, the printed drawings, considered as visual media of communication, are discussed in the ways they take part of school, influencing the processes of teaching and learning, in order to analyze the cultural aspects concerned in its uses. The study is based on a qualitative research developed in the first year class of the school where the researcher studied. Her everyday work, the relations between her and the children, her initial formation, and the ways the printed drawings take part of all these processes constitutes the focus of discussion and analyses.

Key-words: Kprinted drawings, cultural aspects, schooling. 


\section{Aspectos culturais do uso do desenho reproduzido no processo de alfabetização}

Alice Fátima

MARTINS

Neste artigo, são discutidos os modos como os desenhos reproduzidos, entendidos como meios visuais de comunicação, integram os processos de ensinar e aprender no início da escolarização, e suas implicações, com vistas a analisar os aspectos culturais que contextualizam seu uso. As reflexões aqui apresentadas têm como base pesquisa de campo realizada junto a uma turma de início de escolarização e a escola na qual a professora fez sua formação para o magistério, em nível médio. Seu quotidiano, as relações que estabelece com seus alunos, sua formação inicial, e os modos como o desenho reproduzido integra todos esses processos constituem o foco de discussão e análise.

Palavras-chave: desenhos reproduzidos, aspectos culturais, escolarização. 
Os meios visuais de comunicação integram os ambientes escolares, constituídos pelo conjunto de "recursos didático-pedagógicos" que recorrem a estímulos e significações da visualidade em favor do ensino. As denominações meios visuais de comunicação, ou mídias visuais, vêm sendo utilizadas mais recentemente no ambiente educacional. No entanto, Coménio (1985), já no início do século XVII, recomendava o uso da imagem no ensino, referindo-se a ilustrações, figuras, livrinhos de imagens, gravuras.

Os meios de comunicação de que professores e alunos disponham no processo de ensinar e aprender constituem "linguagens culturais em mídias e caracterizam-se como um dos componentes curriculares básicos nas inter-relações educativas de professores e alunos - comunicadores - frente aos conhecimentos" (FUSARI, 1994, p. 12). Nesse sentido, o desenho reproduzido, neste artigo, é analisado como meio visual de comunicação, mídia visual, tendo como eixo de análise os aspectos culturais que contextualizam seu uso.

No ambiente escolar, as informações e expressões estéticas visuais representam um universo pródigo. Elas vão desde a aparência física e estética da escola, os avisos de orientação disciplinar, os projetos de "embelezamento" dos espaços, até os modos como os conteúdos escolares são apresentados aos alunos. A seleção das formas visuais que constituem esse ambiente observa critérios estéticos que fazem parte da cultura escolar, vez que as estampas, os murais, os enfeites, de um modo geral, apresentam uma linha estilística muito própria.

Nesse contexto, os meios visuais de comunicação que auxiliam professores e alunos nas relações com os conteúdos estudados incluem cartazes, ilustrações, desenhos reproduzidos. Este artigo tem como base pesquisa de campo realizada junto a uma turma de início de escolarização, numa escola aqui referida como Escola Classe, cuja professora, aqui referida apenas como Professora, fazia uso de desenho reproduzido em suas aulas, bem como a Escola Normal onde ela fez sua formação em nível médio, aqui referida como Escola de Formação. 


\section{O desenho reproduzido em questão}

O desenho, em suas tantas modalidades de representação gráfica, pode ser reproduzido, o que significa que pode ser multiplicado, repetido. As técnicas de reprodução de imagem, fenômeno relativamente novo na história da humanidade, possibilitaram avanços em vários campos do conhecimento humano, vez que as ilustrações passaram a substituir mais eficazmente as descrições verbais, permitindo que as informações por elas veiculadas fossem assimiladas mais facilmente por maior número de pessoas. Ao longo do século XX, as novas técnicas de reprodução de imagem vieram a permitir não só a reprodução de obras de arte, ampliando ao público em geral as possibilidades de acesso ao acervo artístico da humanidade, como a reivindicar, elas mesmas, o status de formas expressivas de arte, além das funções diversas a que podem atender, dentre as quais as didático-pedagógicas.

No caso do desenho reproduzido, a reprodução pode ser feita por meio de impressoras de grande porte, na forma de material editado à disposição no mercado livreiro, por meio de computadores, máquinas fotocopiadoras, mimeógrafos eletrônicos ou a álcool.

Na Escola Classe e na Escola de Formação, não foi observada a existência de reproduções de obras de arte: as imagens reproduzidas constituem ilustrações gráficas, não-fotográficas, oriundas de livros didáticos e cartilhas, cartazes com desenhos copiados de livros, exercícios ilustrados mimeografados ou, mais raramente, fotocopiados.

Muitas vezes, uma cadeia extensa de reproduções pode ser mapeada desde as fontes de pesquisa do professor até a interação dos alunos com o material reproduzido. Os livros com sugestões de ilustração para os professores são resultado de pesquisa e cópia por parte de seus autores e editores; ao chegarem às escolas, as ilustrações desses livros e outras publicações são copiadas manualmente pelos professores e reproduzidas, seja através do mimeógrafo, fotocopiadoras ou outros recursos. A mão do professor, ao copiar, pode alterar as imagens e os alunos, recebendo o material reproduzido, interferem nele, acrescentam-lhes cores, recortes, colagens. Os alunos encontram nesses modelos as for- 
mas gráficas a serem usadas como esquemas referenciais no decurso de suas aprendizagens.

Na sala de aula, um pequeno desenho do mapa do Brasil ilustra, na cartilha, a palavra mapa. A Professora o reproduziu em diversos exercícios e provas, fazendo uso do mimeógrafo a álcool. Foi copiado tantas vezes, em tantas situações distintas, a cada vez sofrendo alterações na sua forma, que, muitas vezes, não é possível reconhece-lo, visualmente. As deformações da imagem decorrem da manipulação técnica do traçado na sua reprodução e não de uma intenção expressiva ou uma escolha consciente de estilo de representação gráfico-visual.

Entre as várias opções de reprodução de imagem disponíveis nos ambientes escolares, a mimeografia figura entre as mais comuns, pelo baixo custo operacional e fácil manipulação do equipamento. A popularidade do mimeógrafo nos ambientes escolares é muito posterior à xilogravura e à litogravura, técnicas de impressão largamente usadas por artistas plásticos e ilustradores há muitos séculos. Mais recentemente, outros recursos tecnológicos estão à disposição dos professores facilitando a cópia e a reprodução dos materiais escolares. Dentre esses, estão as máquinas fotocopiadoras. O desenvolvimento das tecnologias de impressão ampliou a oferta, por parte de editoras especializadas, de revistas e livros com ilustrações para colorir, tratando de temas relativos aos conteúdos escolares e de outros interesses, tais como meio ambiente, flora e fauna, filmes recentes com sucesso de público.

Isto posto, neste artigo, o termo desenho reproduzido refere-se a todas as representações gráficas de desenhos, ilustrações, imagens passíveis de serem multiplicadas de diversas formas. Fazem parte desse universo, tanto a impressão gráfica de grande porte - livros, cartazes, ilustrações produzidas por editoras e adquiridas pelas escolas - como as fotocópias e as mimeografias.

\section{Desenho reproduzido: "trabalhando com o concreto"...}

No planejamento de suas aulas, a Professora seleciona aquelas imagens que melhor representem a "realidade concreta" de acordo com os seus objetivos de ensino e com os códigos visuais 
que compõem o universo visual da escola. A função representacional não é explicada pela imagem em si, enquanto nível de detalhamento da forma, "realismo", mas de acordo com o contexto sócio-cultural de produção e comunicação de informações no qual a imagem é veiculada, com a função a ela atribuída nesse contexto.

Assim, as ilustrações de textos, os desenhos para serem coloridos, os cartazes são trazidos para o ambiente de sala de aula para substituir a realidade, simulando a interação do aluno com o concreto. Essa interação é entendida como importante no processo de aprendizagem. A Coordenadora Pedagógica e a Professora explicam que os desenhos são mais usados no início da alfabetização, pela necessidade de "se trabalhar mais o concreto com o aluno". O concreto, nesse caso, é a representação visual dos objetos reais.

O entendimento de que, no início de escolarização, é necessário que os conteúdos sejam trabalhados no nível concreto advém, em parte, da popularização nem sempre com o devido esclarecimento de alguns conceitos da teoria construtivista ${ }^{1}$, de acordo com os quais, o desenvolvimento do pensamento se dá em etapas. Por volta dos sete anos, a criança é capaz de realizar operações, de elaborar hipóteses e testá-las atuando diretamente sobre a realidade concreta. Piaget denomina essa etapa de operatório-concreta ${ }^{2}$. Contudo, tanto a justificativa para a possibilidade de experimentação no nível concreto, quanto a tradução do que seja o concreto na dinâmica escolar, não levam em consideração os conceitos e pressupostos da teoria em questão.

Assim, o desenho colorido, recortado conforme instruções, que deve ser interpretado sob as orientações da Professora, pretende substituir a vivência da realidade concreta. Em contrapartida, a experiência concreta de vida dos alunos, que trazem uma bagagem significativa de informações vivenciais e culturais, tem espaço restrito de expressão na escola.

No entanto, não há garantia de que a realidade representada por meio dos desenhos e das ilustrações no ambiente escolar, do modo como ocorre, seja significativa, reconhecível para os alunos, apesar das convenções estabelecidas em sala de aula, ao longo dos procedimentos de ensino. A Professora explicita sua 
preocupação assim: "Os desenhos são escolhidos a partir da realidade dos alunos. Eu tiro da realidade deles. Nunca uso desenho que para eles seja abstrato. Por exemplo, falar da lua, falar das fases da lua, é uma coisa absolutamente abstrata para eles, que foge completamente ao entendimento deles. Falar do mar é uma coisa abstrata”. Assim, é a própria Professora quem decide quais as imagens estão de acordo com a vivência e a capacidade interpretativa dos alunos, embora ela própria não compartilhe a realidade sócio-cultural dos alunos, oriunda de outro segmento social, habitante de outro contexto. É com base no valor de troca do capital cultural dos alunos que a Professora estabelece esses critérios, tendo como contexto referencial o seu próprio capital cultural traduzido em hábitos, práticas pedagógicas, amplamente justificadas (BOURDIEU, 1987).

Através das ilustrações selecionadas de acordo com critérios estabelecidos pela Professora, com as quais os alunos interagem, são trazidos, para dentro da sala de aula, desenhos de gatos e ratos, circos e palhaços, animais diversos, paisagens, objetos, pessoas, flores, tantas imagens comunicadoras de cultura, alheias ou não à realidade dos alunos. De um modo geral, tais ilustrações resultam de processos de simplificação e estilização da representação gráfica. Uma análise mais detalhada não reconhece, nelas, a intenção de "representação fiel à realidade", ainda que cumpram a função de estar no lugar de tal realidade, "do concreto" a ser apresentado aos alunos. No processo de alfabetização, as imagens funcionam como uma complementação representacional à palavra escrita e lida: os objetos e eventos são representados pela palavra e pela imagem, sendo, gradualmente, substituída pelas palavras, à medida que o aluno vai sendo alfabetizado.

No tocante às deformações sofridas pelas imagens nos processos de reprodução, a Diretora da Escola relata que, em determinadas situações, ela própria não consegue identificar o desenho dos exercícios preparados pelos professores:

- Uma coisa que eu vejo em relação ao desenho e à forma, é que, às vezes, o aluno não conhece determinadas frutas ou coisas como se fosse o desenho. Então, às vezes eu também vou dar uma aula e não sei que desenho é aquele... A gente tem que cuidar, porque às vezes 
a gente quer inventar a jaca, e desenha como uma maçã... Isso também é uma coisa que confunde o aluno. Tem as pessoas que costumam, de primeira à quarta, desenhar muito, p'ra eles só botarem as palavrinhas, fazer auto-ditado ${ }^{3}$, porque eles estão só começando a escrita mesmo, p’ra fazer a interpretação do que eles tão vendo. Aí, às vezes, o professor quer contribuir, mas acaba colocando coisas que não são da realidade do aluno, que eles copiam dos livros didáticos, quando poderia ser uma coisa mais concreta, né? Da própria linguagem que eles têm no cotidiano. Então eu acho que isso é um lado que a gente teria que trabalhar mais e que ainda não está sendo trabalhado na escola.

Na Escola Classe, portanto, as ilustrações têm a função básica de mediar as relações de professores e alunos com os conteúdos escolares, expandindo visualmente o alcance da mensagem verbal: o desenho facilita a compreensão do conteúdo, por parte dos alunos; a ilustração ajuda a fixar a palavra aprendida e ambienta a produção escrita dos alunos; os adornos desenhados tornam menos ameaçadoras as provas e os deveres. Como a principal função das ilustrações e dos desenhos escolares é substituir a realidade concreta e expandir a informação verbal transmitida para o aluno, as questões estéticas da arte propriamente dita não estão diretamente envolvidas.

Mas, na dinâmica da apresentação dos elementos visuais, na composição, de acordo com o estilo das imagens correntes, estão implícitas relações que interferem na percepção e comunicação das informações transmitidas e recebidas. As relações composicionais reforçam idéias, conceitos, sensações. Mesmo sem formação artística, ou no campo da programação visual, a Professora, ao selecionar e reproduzir imagens, cria espaços visuais de comunicação, que podem ser mais ou menos eficientes no alcance de seus objetivos, de acordo com a observância de princípios gerais que os norteiam.

Williams (1995) aponta quatro princípios básicos de acordo com os quais uma página pode ser diagramada, tendo-se em vista a eficiência da comunicação visual: a proximidade, o alinhamento, a repetição e o contraste. Em geral, as pessoas sem formação na área organizam suas "páginas" com "palavras, frases e imagens espalhadas, preenchendo cantos e ocupando muito espaço, de maneira que não sobre espaço livre. 
Parece haver certo medo dos espaços vazios” (p. 15). A ocupação de todo o espaço com palavras, frases e imagens dificulta o acesso do leitor às informações, em função da aparência desorganizada. Se nada deve ser colocado arbitrariamente em uma página, cada item deve estar conectado visualmente a outros. A proximidade, o agrupamento de itens relacionados entre si, e o alinhamento garantem a organização das informações. A repetição de elementos visuais dá consistência ao material e o contraste, além de acrescentar um "atrativo visual" à página, cria uma hierarquia organizacional entre os diferentes elementos.

Os professores das Escolas de Formação e a Professora organizam seus exercícios sem considerar os quatro princípios citados por Williams (1995). Em geral, as figuras grandes aparecem centralizadas na folha, as ilustrações de texto são distribuídas por todo o espaço, os desenhos, cuja função é "ornamentar" os textos, ocupam eventuais campos vazios. Do mesmo modo, na Escola de Formação, a professora da disciplina Materiais de Ensino Aprendizagem enfatiza a necessidade de clareza das informações apresentadas e a importância do desenho da letra e da qualidade visual do material, quesitos cobrados aos seus alunos. Suas orientações são: distribuição dos elementos por toda a página, ou centralização dos elementos; adoção de letra cursiva para os textos; desenhos ilustrativos compondo com os textos ou desenhos ornamentais delimitando as margens e complementando os espaços.

$\mathrm{Na}$ Escola, o material distribuído para os alunos carece, em geral, de qualidade tanto de diagramação quanto de impressão. As páginas das cartilhas adotadas são as referências para a organização dos exercícios mimeografados. Pequenos retângulos e outras formas geométricas delimitam os espaços dos desenhos e textos. Ainda que as informações visuais tenham boa organização no preparo do estêncil, por ocasião da reprodução, muitas vezes ocorrem manchas, a folha é impressa em diagonal e o traçado perde nitidez, de modo que a leitura da imagem e das palavras fica comprometida. 


\section{O desenho reproduzido: questões de estilo e de função}

Ainda que a qualidade da programação visual e estética dos desenhos reproduzidos não seja levada em consideração, resta, ainda, indagar se eles apresentam um estilo visual reconhecível. $O$ estilo pode ser considerado como sendo a conjunção dos traços pessoais de quem produz a forma e do meio cultural no qual a forma é produzida. Ostrower (1989, p. 79) lembra que toda forma, ainda que destituída de quesitos estéticos que a tornem artística, significa algo, contém valores. Ela define forma como sendo estrutura e ordenação, "algo em si delimitado, mas não no sentido de uma área demarcada por fronteiras". Essa definição é válida para as formas de pensamento, as manifestações verbais, o gesto, como também para as manifestações visuais, não-verbais.

Portanto, as formas visuais encontradas no ambiente escolar não são aleatórias, mas escolhidas, produzidas e reproduzidas pelos membros da comunidade escolar, de acordo com critérios estabelecidos desde o contexto no qual estão inseridas, a partir dos quais são discriminados o feio e o bonito, o útil e o dispensável, o artístico e o pedagógico.

Alguns fatores contribuíram e contribuem, historicamente, na constituição desse estilo visual. Primeiramente, as influências históricas no que dizem respeito à ilustração de textos em geral, ao uso de ilustrações a serviço da educação e à influência da escola Neoclássica na concepção das artes no Ensino Normal no Brasil. A intersecção dessas correntes levou à formação de uma cultura escolar no âmbito das representações visuais, segundo a qual as imagens são importantes no auxílio do processo de ensino: imagens-estampa para serem impressas, reproduzidas, copiadas, ensinadas para os alunos.

Um outro fator parece ter sido muito importante no estabelecimento do "gosto visual" dominante nas escolas: a feminização do magistério de início de escolarização. Na sua instalação, a Escola Normal representou, para a mulher, uma das poucas oportunidades de prosseguimento nos estudos e, ao mesmo tempo, de atuação profissional: o magistério. No entanto, desde a sua origem, o magistério foi visto como uma extensão dos afa- 
zeres domésticos femininos, uma atividade "maternal". Dentro dessa visão, a mulher parece ter levado para o seu ambiente de formação e, como professora, para o ambiente de trabalho - a sala de aula - o seu "modo de ser doméstico". As "riscas de bordado" passaram a constituir os critérios de seleção das imagens usadas no processo de escolarização.

Em relação à feminização e às imagens selecionadas, é interessante ressaltar alguns exemplos que ilustram o quanto essa referência está incorporada à cultura do magistério. Muitas das figuras escolhidas pela Professora podem ser encontradas em estampas de cartões de aniversário, de objetos e outros adornos domésticos. Na Escola de Formação, a Coordenadora Pedagógica comenta sobre a tendência dos alunos do Curso Normal em fazer uso excessivo de enfeites nos seus cadernos e trabalhos. A Professora de Estudos Sociais apresenta o seu plano de curso e todos os materiais produzidos pelos alunos, guardados em envelopes com diferentes dobraduras e recortes delicados, com desenhos que enfeitam as folhas nas quais os envelopes são colados. Ela mostra o seu caderno de Recreação e Jogos, da época em que era aluna na mesma Escola de Formação de Professores, no início da década de 70. O padrão visual do caderno segue o mesmo estilo que hoje ela imprime ao material oferecido para seus alunos.

Vale ressaltar que o espaço ocupado pelas Artes Visuais na Escola de Formação é tímido, ainda que a ele seja destinada uma carga horária de duas aulas semanais nos primeiro, segundo e quarto anos de formação, com a denominação de Educação Artística. A Assistente Pedagógica comenta que seu ensino está orientado, atualmente, para as questões mais específicas do ensino das Artes Visuais, embora, em momentos anteriores, tenha seguido outros princípios. À época em que a Professora freqüentou o curso, o ensino de Arte esteve voltado prioritariamente para as Artes Aplicadas. O que confirma o seu relato de que não aprendeu "a desenhar", tampouco recebeu orientações sobre o desenho no processo de ensino, mas aprendeu técnicas para fazer "utilidades para o lar com arte, por exemplo, a pintar tábua de carne para enfeitar a parede da cozinha".

As Artes Aplicadas estão presentes na formação do profes- 
sor em nível médio desde a criação das Escolas Normais no Brasil. O primeiro Plano de Estudos de formação dos professores primários já apresentava "Trabalhos de Agulha (para meninas)" como um tópico a ser desenvolvido no terceiro ano do curso (BRZEZINSKI, 1987, p. 104). Ao que indicam os relatos, na Escola de Formação, quando as Artes Aplicadas deixaram de compor o currículo, seus conteúdos foram incorporados pela a área de Arte. Por sua vez, à Didática Geral e às Didáticas das disciplinas específicas continuou sendo atribuída a responsabilidade pelas orientações quanto ao uso das imagens impressas no ensino dos diversos conteúdos escolares, num contexto em que os desenhos reproduzidos cumprem o papel de instrumentos portadores das mensagens ou informações a serem comunicadas. O que evidencia a relevância do ato de escolha do meio (mídia) a ser adotado, sendo, portanto, necessário avançar na compreensão do mesmo.

\section{As artes aplicadas, o desenho e o ensino de arte na formação dos professores de início de escolarização}

No Brasil, apenas em 1880 foi criada a primeira Escola Escola Normal no Município da Corte, com um curso de três anos de duração (AZEVEDO, 1996). O "Regulamento para a Escola Normal da Capital Federal da República dos Estados Unidos do Brasil", assinado por Benjamin Constant Botelho de Magalhães em 8 de novembro de 1890, define que as "materias que fazem objecto do ensino nesta Escola são": Português, Latim, Francês, Geografia, História Universal, Matemática, Astronomia, Física e Química, Biologia, Sociologia, Moral, Noções de Agronomia, Desenho, Caligrafia, Música, Ginástica, Trabalhos de agulha "para o sexo feminino", Trabalhos manuais "para o sexo masculino”. O Desenho incluía o "estudo geral do traço à mão livre (stimographia), Desenho Geométrico, inclusive o das ordens arcthictetonicas e o de machinas simples, Desenho topográfico, Desenho de ornato, de paisagem e de figura" (Revista Pedagógica, 1890, p. 134 - 137).

Às artes manuais na escola primária eram atribuídos os objetivos de "desenvolver as qualidades physicas, intellectuaes 
e moraes do futuro cidadão, de auxiliar o menino a encontrar (...) a carreira apropriada às suas disposições naturaes (...)" (Revista Pedagógica, 1893, p. 274). Em relação à formação do professor, julgava-se que ele precisasse apenas dominar os princípios básicos das atividades, sem ser artista ou artesão. Essa argumentação apoiava-se na orientação, de então, para o ensino do desenho para o início de escolarização, segundo a qual o professor poderia demonstrar os princípios do desenho sem ser desenhista.

No que se refere ao ensino de um modo geral, desde a instalação do império até o início do século XX, alguns traços marcaram a formação do professor para o início de escolarização: o predomínio da formação em nível secundário, a feminização do magistério primário, a desobrigação da União para com os ensinos primário e normal, e a prática pedagógica tradicional, centrada na pessoa do mestre-escola, cuja formação estava voltada para que cumprisse o papel de transmissor do acervo cultural aos alunos. Aos alunos, no processo ensino-aprendizagem, cabia a armazenagem passiva das informações. Essa prática era estendida para o ensino do Desenho, que centrava-se na cópia de reprodução de modelos e estampas. $\mathrm{Na}$ Escola Classe, essas marcas iniciais do ensino primário e da formação de seus professores estão ainda presentes: o desenho restringe-se à cópia de imagens, à reprodução de estampas, que pressupõe a atitude passiva dos alunos na execução das tarefas solicitadas.

$\mathrm{Na}$ década de 20, o país conheceu acentuado desenvolvimento na indústria e crescimento dos centros urbanos, ingressando, então, no "modelo capitalista-urbano-industrial" (BRZEZINSKI, 1987, p. 51). As transformações econômicas e a expansão dos centros urbanos deflagrou um movimento reformador da Cultura e da Educação. Direcionadas prioritariamente para os ensinos primário, normal e técnico, as reformas marcaram um período de grande importância no desenvolvimento de uma política nacional de Educação. O ideário escolanovista norteou tais reformas, que tinham por princípio o reconhecimento de que os homens são essencialmente diferentes, devendo ser respeitados. De acordo com esse pensamento, os conteúdos esco- 
lares deveriam partir das experiências vividas pela criança. $\mathrm{O}$ ensino de arte e o de desenho que receberam as influências da Escola Nova seguiram esse princípio, defendendo a livre-expressão, a espontaneidade e a experimentação das formas de expressão pela criança. Nesse contexto, cabe ao professor não ensinar, mas criar o ambiente propício e estimulador para que a criança exercite o seu potencial criador.

No entanto, as concepções do ensino de arte assentadas nos princípios da Escola Nova não chegaram a atingir a escola regular e tampouco as escolas de formação dos professores de início de escolarização. A fala do educador Augusto Rodrigues (1960), por ocasião do IV Congresso Nacional de Professores Primários, ocorrido em 1960 em Recife, é explicitadora do descompasso entre as concepções que se desenvolveram sobre o ensino de Arte dentro e fora das escolas primárias. Sustentava, então, o professor, que "a vida, sem a dimensão da criatividade, é limitada e estéril. (...) A expressão da criança, (quer se trate de desenho, de jogos simbólicos ou de dramatizações espontâneas) é condição indispensável ao processo da estruturação de sua vida psíquica e, por onde, de seu amadurecimento" (p. 64). Em defesa do que chamou de aparelhamento material e ideológico da escola primária para propiciar às crianças o exercício da capacidade expressiva, acrescentou que

as Escolinhas de Arte do Brasil teriam recompensados muitos de seus esforços se (...) conseguissem dar ao magistério brasileiro a consciência de que a Arte não é apenas mais uma disciplina do currículo, (...) mas uma disciplina fundamental que está na base de todas as outras, pois que seu objetivo é o de prover a criança dos meios de encontrar a si própria e a realidade que a cerca ( $\mathrm{p}$. 65-66).

O movimento reformista ocorrido a partir da década de 20 congregou os maiores educadores brasileiros que formaram um conjunto heterogêneo de idéias que convergiam em dois pontos: no "entusiasmo pela educação" e no "otimismo pedagógico", ou seja, no reconhecimento, na educação, da solução para os principais problemas sociais do país, e na crença de que determinadas formulações doutrinárias internas à escola bastariam para indicar o caminho para a verdadeira formação 
do homem brasileiro, sem levar em consideração o contexto sócio-cultural no qual a instituição escolar está inserida (BRZEZINSKI, 1987).

A despeito de alguns avanços observados no início do século XX no ensino de arte e do desenho, nas escolas elementares e secundárias do país, decaiu o interesse pelo ensino de arte, ao mesmo tempo em que houve uma valorização das figuras e imagens estereotipadas em sala de aula. O que ocorreu, então, foi uma divisão de águas: de um lado, o movimento fora das escolas regulares, voltado para as pesquisas e estudos quanto às questões relativas ao ensino da arte e do desenho; de outro, a manutenção, nas escolas regulares, das condutas pedagógicas que vinham sendo adotadas desde o século XIX.

Apesar da aparente diminuição do espaço destinado às artes na formação do professor primário, a década de 60 caracterizou-se por uma retomada do interesse da escola regular pelo ensino de artes. Tanto que, no início da década de 70, a Lei n $5692 / 71$ tornou obrigatório o ensino de arte no ensino básico, com a denominação Educação Artística. $\mathrm{O}$ ensino de $1^{\circ}$ e $2^{\circ}$ graus também foi reformulado, bem como a política de formação dos professores. Como tônica geral, o ensino de $2^{\circ}$ grau passou a priorizar a profissionalização e a formação para o exercício do magistério para as séries iniciais feita neste nível, transformou-se em habilitação, fazendo parte do conjunto de habilitações profissionais. Assim, a Lei $n^{\circ} 5692 / 71$ descaracterizou a Escola Normal como lócus de formação do professor. A Habilitação Específica de $2^{\circ}$ Grau para o Exercício do Magistério de $1^{\circ}$ Grau foi normatizada pelo parecer $n^{\circ} 349 / 72$, do Conselho Federal de Educação. Por força desse parecer, a Educação Artística compunha o núcleo comum obrigatório do currículo. Nesse contexto, a Habilitação para o Magistério passou a obedecer "à mesma rigidez de estrutura curricular que as demais habilitações de $2^{\circ}$ Grau" (SALVIANO, 1995, p. 25).

A LDB 9394/96 revogou a Lei $n^{\circ} 5692 / 71$, em dezembro de 1996, e não provocou alterações significativas no ensino de Arte destinado à formação do professor de séries iniciais do ensino fundamental. 


\section{O desenho reproduzido na estrutura curricular da Escola de Formação}

$\mathrm{Na}$ Escola de Formação, as orientações quanto ao uso do desenho e de outros meios visuais de comunicação no ensino não estão restritas à área de arte, à disciplina Educação Artística. Embora as concepções sobre o ensino de arte estabeleçam referenciais que norteiam, em alguma medida, a adoção do desenho no ensino em geral, e no início de escolarização, na Escola de Formação são veiculadas diferentes concepções sobre o desenho no ensino, de acordo com diferentes disciplinas do currículo. Ou seja, além da disciplina Educação Artística, também a Didática Geral e as Didáticas das outras áreas de conhecimento tratam dos chamados "recursos visuais" diversos: cartazes, ilustrações, estampas, rótulos, maquetes, como também os desenhos reproduzidos.

A mais, na disciplina Material de Ensino Aprendizagem, são desenvolvidos tópicos como confecção de material didático, técnicas de estudos, desenho de letras (cursiva, imprensa, normógrafo, letras para cartazes e murais), elaboração de estêncil (medidas, escrita no estêncil), utilização do estêncil, funcionamento e manuseio do mimeógrafo a álcool, transparência e retroprojetor, uso do quadro de giz, álbum seriado, entre outros.

Já em artes visuais, é priorizada a metodologia do ensino de arte para o início de escolarização, enfocando os fundamentos da Educação Artística, o desenvolvimento da criança e as possibilidades de integração com as outras áreas do conhecimento. No entanto, a inserção da Educação Artística no currículo é acanhada, em contraponto ao núcleo de Didática, considerado eixo central da formação. Os professores de Didática reconhecem a importância da área de arte, exercitando sua autoridade legitimadora: "no caso de todas as Didáticas, as artes são um suporte muito grande..." Segundo eles, o domínio de Artes é importante para a produção do material pedagógico. Defendem a idéia de que "a imagem ajuda a criança a visualizar e se soltar na sua expressão oral". É importante notar que tal argumento foi apresentado também pela Professora, na Escola Classe, que adota a "redação baseada na imagem". A 
Professora de Didática sugere que os professores "perguntem o que as crianças vêem no desenho, elas podem ver o que não está ali, a partir da sua experiência pessoal". As imagens podem estar em cartazes, gravuras impressas, em colagens sem palavras, por exemplo.

\section{A formação do professor formador do professor de início de escolarização}

As concepções de ensino trabalhadas junto aos alunos-futuros-professores constituem o universo de compreensão do ensino dos professores que ensinam e que, por sua vez, refletem a sua formação, numa cadeia que se alonga no tempo, impregnando-se de referenciais históricos e culturais. Alguns dados levantados nesta pesquisa apontaram para possíveis mecanismos de manutenção de práticas de ensino. Os ambientes de formação mostraram-se acentuadamente conservadores em suas propostas de ensino.

Na Escola de Formação, parcela significativa dos Professores de Didática habilitou-se para o magistério em Escolas Normais, tendo cursado, posteriormente, Pedagogia ou Licenciatura em Letras, Matemática e outros. A Professora de Didática de Estudos Sociais, habilitada para o magistério de séries iniciais, passou a atuar como professora na Escola de Aplicação dessa Escola. Posteriormente, tendo concluído o curso de Pedagogia, passou a atuar diretamente na formação de professores. Seu caderno "de quando era aluna", no início da década de 70, tem os conteúdos ilustrados e as folhas enfeitadas com imagens recortadas e coladas. Tal estilo visual manteve-se, podendo ser observado no material pedagógico distribuído para os seus alunos em formação atualmente. Exercendo, portanto, ainda hoje, influências na formação dos professores.

O Professor de Educação Artística que atua na Escola de Formação é formado em Educação Artística, Licenciatura Plena. Barbosa (1996) esboça um perfil da formação em nível universitário dos professores de Arte em geral, inclusive aqueles habilitados para atuar no ensino médio, portanto, na formação dos professores de início de escolarização. Baseado em pesquisas diversas, esse perfil aponta para lacunas graves no processo 
de formação dos professores de Arte na universidade. A autora denuncia que a educação artística e estética que compreenda a dimensão histórica da produção artística, a compreensão de uma gramática visual e a auto-expressão através do fazer artístico estão longe de serem prática correntemente realizada por esses professores, ainda que portadores de titulação. Em artes visuais, há um predomínio do ensino do "Desenho Geométrico, o laissez-faire, temas banais, as folhas para colorir, a variação de técnicas e o desenho de observação, os mesmos métodos, procedimentos e princípios ideológicos encontrados (...) em programas de ensino de artes entre 1971 e 1973" (BARBOSA, 1996, p. 12), o que aponta para a manutenção da prática pedagógica que reflete, em alguma medida, a qualidade da formação desses professores.

\section{O desenho reproduzido e sua dinâmica na alfabetização}

Ao analisar as relações entre o desenho e a escrita, Pillar (1996a) considera ambos como sistemas de representação gráfica ao mesmo tempo distintos e complementares. A autora entende que a representação é gerada a partir da possibilidade da criança reconstruir em pensamento, por meio de signos ou símbolos, os objetos ausentes. As representações podem seguir algumas condutas: a imitação, o jogo simbólico ou do faz-de-conta; o desenho, ou imagem gráfica, a imagem mental, ou imitação interiorizada, a evocação de ações passadas através da linguagem verbal, que é passível de registro gráfico. A origem gráfico-representativa é apontada por Ferreiro (1994) como comum à escrita e ao desenho. Ao longo de suas aprendizagens a criança passa a fazer as distinções entre texto e imagem. Por essa razão, a ideografia é parte indispensável na elaboração dos materiais didáticos para processos de alfabetização. Segundo Ferreira (1986), a palavra ideografia significa a representação de idéias por meio de sinais que reproduzem objetos concretos. A ideografia, em uma cartilha, forma, assim, um conjunto de ideogramas, ou informações figurativas que substituem ou facilitam a leitura da palavra escrita, auxiliando a criança na decodificação 
dos significados enquanto ela ainda não está alfabetizada.

As representações ideográficas constituem uma etapa na evolução histórica da escrita, cujo último estágio foi a criação do alfabeto. Ideografia é um conceito muito referido pelos autores que discorrem sobre o método de alfabetização adotado pela Professora, o silábico, que integra os chamados métodos sintéticos, que partem da identificação de um elemento da palavra para chegar à formação do todo significativo: palavra, sentença, história. A Professora escolhe as palavras-chave e suas imagens correspondentes, das quais retira a sílaba ou letra (vogal ou consoante) que pretende ensinar. É formada, então, a família silábica, através da associação dessa letra a cada uma das vogais. Novas palavras são estudadas, a partir da família silábica em estudo.

Considerando a conceituação de ideografia, é importante notar que o conjunto de ilustrações das cartilhas adotadas e de outros materiais distribuídos durante o ano letivo nem sempre corresponde ao conhecimento visual e conceitual que os alunos vivenciam em seu ambiente cultural extra-escolar. Muitas vezes pode acontecer que a palavra escolhida pelo aluno para decodificar a imagem não corresponda à palavra solicitada pelo exercício mimeografado, pela cartilha. Decorre que, freqüentemente, crianças lêem a informação visual diferentemente da intenção do ilustrador. O que, de algum modo, é previsível, considerando-se que a ilustração é produzida a partir do universo subjetivo visual do ilustrador, no seu contexto cultural, para ser decodificada pela criança com sua subjetividade e ambiência cultural diferenciada em relação ao ilustrador. Além desse aspecto, deve ser considerada a natureza do código visual ideográfico, uma vez que a representação relaciona-se à idéia no seu contexto geral e não à palavra específica.

Para exemplificar, na classe de alfabetização, um aluno demonstrava seu domínio da leitura, percorrendo aleatoriamente páginas da cartilha, decodificando palavras e figuras, às quais atribuía nomes de acordo com o seu reconhecimento visual. Em algumas situações, sua interpretação correspondia ao solicitado, na maioria das vezes, ele atribuía outras palavras: prato para a ilustração da palavra tigela, ovo para gema, cavalo para burro, boi para zebu. É preciso notar que, nesse exercício, o alu- 
no efetivamente realizava a leitura das imagens, amparando-se em sua própria vivência visual cultural. Essa leitura não deve ser desconsiderada, muito embora não corresponda à expectativa da escola no sentido da aprendizagem dos códigos da língua escrita. Esse aluno foi considerado pela professora como "imaturo para ser alfabetizado", avaliação suficiente para que fosse incluído entre os alunos destinados a repetir a primeira série do ensino fundamental.

Ferreiro e Teberosky (1985), em uma pesquisa, abordam as relações entre desenho e escrita, tendo como suporte teórico os estudos de Piaget sobre os modos como as crianças aprendem a usar diferentes representações para evocar objetos e assuntos ausentes. Nos sistemas de linguagem, o desenho e a escrita cumprem essa função, embora difiram em sua natureza. O desenho mantém uma relação icônica com o que está sendo representado, enquanto que a escrita, não. Os símbolos adotados para a escrita são convencionalmente determinados e mantêm uma relação não-visual de representação dos sons da palavra oralizada. A escrita representa os sons e não a sua idéia ou significado das palavras. Assim, embora a escrita mantenha relações estreitas com o desenho, constitui objeto específico de representação.

As autoras apontam modos distintos de estabelecimento dessas relações em diferentes estágios do desenvolvimento da criança. Para algumas crianças não há diferenciação entre desenho e escrita. Outras observam que são diferentes, mas consideram que a escrita representa o nome do desenho. Tal hipótese é denominada pelas autoras como "etiquetagem", um passo importante no processo de conceitualização da escrita. Situo nesse estágio o aluno que "lia" as palavras decifrando as ilustrações correspondentes, pois ao fazê-lo, ele identificava as palavras como "etiquetas" das figuras desenhadas. No estágio subseqüente a esse, as crianças já são capazes de reconhecer que a imagem não antecipa inteiramente o texto que lhe corresponde, de modo que cada uma das linguagens - desenho e escrita - possui propriedades específicas.

Assim, ao interpretar uma imagem, ou seja, ao descrever uma imagem, a criança, ainda que não realize uma leitura no sentido estrito, de fato lê, estabelecendo os princípios básicos 
para o seu ingresso no universo da palavra escrita socialmente reconhecida. No início, a Professora privilegia as atividades de coordenação motora e viso-motora,: tratam-se de exercícios de preenchimento de linhas pontilhadas e espaços delimitados "observando-se os limites", repetição de padrões de linhas, "quebra-cabeças" cujo desafio é completar figuras, entre outros. As cartilhas oferecem várias sugestões nesse sentido. A ênfase em exercícios que visam à coordenação motora, nesse período da escolarização, deve-se à dicotomia entre corpo e mente, manual e intelectual, ação e pensamento, presente na escola. Priorizam-se, então, as atividades intelectuais, para as quais os alunos oriundos de segmentos sociais mais pobres, de um modo geral, demonstram dificuldades, em detrimento daquelas que envolvem o fazer manual, a atividade corporal. A afirmação que se segue sintetiza as prioridades: "Aqui a gente se preocupa com o ler e o contar. E só isso já é um desafio muito grande". Na Escola Classe, as atividades manuais e corporais restringem-se a algumas propostas de recorte e colagem, ao horário do lanche, quando há uma certa movimentação dos alunos pela sala. A suspensão do recreio na escola e a orientação para que os professores não programem atividades fora da sala de aula restringem ainda mais as possibilidades desse tipo de atividade.

Os exercícios de coordenação motora adotados na escola, baseados em desenhos reproduzidos, têm por objetivo "preparar" os alunos para serem alfabetizados. Considera-se que nem todos os alunos chegam à escola com as habilidades necessárias para iniciarem o processo de alfabetização, por isso é previsto um "período preparatório em que se fará o treinamento, tendo em vista a prontidão para a leitura e a escrita" (BRAGANÇA, 1989, p. 4). Carvalho (s.d.) acrescenta que

as atividades desenvolvidas no período preparatório de exercícios de coordenação viso-motora devem ser relacionados à área de leitura e escrita de palavras-chave que estão na cartilha a ser utilizada. Isto possibilitará à criança a compreensão dos significados dos vocábulos que nortearão o estudo das famílias silábicas (p. 149).

A Professora, no período preparatório, realiza exercícios em folhas sem pauta, com desenhos para serem coloridos com giz 
de cera e tinta, vogais grandes e números com ilustrações que ocupam todo o espaço do papel. Ela refere-se ao fato de os alunos serem muito tímidos no início do ano, o que requer atividades que estimulem a sua expressão verbal e a interação entre os colegas. Ao longo do ano letivo em que esta pesquisa foi realiza$\mathrm{da}$, os alunos coloriram os desenhos fazendo uso de giz de cera, lápis de cor e canetas hidrocor.

Quanto à "prontidão" dos alunos para serem alfabetizados, todos os profissionais da escola foram unânimes em observar que a carência de salas ou centros voltados para a Educação Infantil resulta na chegada dos alunos à escola regular sem qualquer vivência com os diversos materiais escolares. Crianças oriundas de comunidades pobres, com baixo nível de escolaridade, têm pouco contato com material escrito em suas casas. A intimidade com papéis, canetas, cadernos, livros, dentre outros, implica no acesso a um capital cultural legitimado pela instituição escolar. Como esses alunos, oriundos das camadas mais pobres da população, não trazem na sua bagagem tais "moedas", são apontados como "imaturos". A expectativa da escola, em geral, é baixa quanto às probabilidades de sucesso desses alunos na escolarização.

Prontidão é uma palavra muito usada pela Professora, que se refere a um conjunto de habilidades mínimas necessárias para que o aluno possa começar a ser alfabetizado, envolvendo, principalmente, coordenação motora e viso-motora. No entanto, esse conceito é questionado por alguns estudiosos, que apontam a condição de prontidão como sendo artificialmente imposta à criança. Com base em pressupostos construtivistas, Ferreiro (1994) explica que a criança, em diferentes estágios, desenvolve diferentes hipóteses sobre o ato de ler e escrever, exercitando-as, testando-as, num processo gradual de construção da escrita propriamente dita enquanto sistema de representação. Cabe ao professor reconhecer tais hipóteses e estimular a criança a avançar na direção da escrita convencional, culturalmente produzida e socialmente aceita, e da leitura. Desse modo, não há um conjunto específico de habilidades que capacite a criança a ser alfabetizada, mas, em cada momento do seu desenvolvimento, a criança dispõe de um conjunto de esquemas de pensamento a partir das 
quais o professor deve propor suas estratégias de ensino.

Além disso, o princípio da prontidão desconsidera que, além da complexa coordenação mecânica das ações do olho, mão e ouvido, há um ser cognoscente, histórico e cultural que articula o signo, a palavra, que pensa e elabora hipóteses sobre o que se lê e o que se escreve, sobre o que se desenha, sobre as imagens que comunicam informações, conceitos, emoções, um ser que produz conhecimento, este entendido como conjunto de explicações acerca de determinados eventos com os quais a pessoa entre em contato.

As crianças chegam à escola com uma bagagem vivencial-cultural que não corresponde à bagagem solicitada pelo ambiente escolarizado. Por um lado, esse capital trazido pelos alunos tem baixo valor no universo escolar; por outro, eles estão precariamente instrumentalizados para apropriar-se do capital cultural apontado pela escola, o que requer, deles, o cumprimento de uma empreitada penosa. Por sua vez, a escola toma as dificuldades apresentadas pelos alunos como o principal argumento para justificar a minimização dos conteúdos, a "facilitação" dos procedimentos, o "apressamento" dos períodos de preparação. Todas essas decisões acarretam a diminuição das expectativas, por parte da escola, de sucesso nas aprendizagens, que são assimiladas pelos próprios alunos.

Decorre que a qualidade das informações oferecidas aos alunos, dos textos que formam a base da alfabetização, das imagens que ilustram os conteúdos ou que compõem as atividades em arte é passível de questionamento. A apropriação desse capital, o qual é universal e que, segundo o discurso da escola democrática, deveria ser acessado por todos os cidadãos, torna-se, cada vez mais, inviabilizada para esses alunos.

À medida que o processo de alfabetização avança, diminui o número de ilustrações utilizadas. Estas passam a assumir, predominantemente, um papel de ornamentação de exercícios, provas e outros instrumentos de ensino. Isto se justifica pela maior ênfase, nas séries mais avançadas, nos conteúdos escolares e pela menor necessidade de buscar estímulos visuais diferenciados para esses alunos.

O método de alfabetização observado tem na repetição e 
na memorização estratégias importantes de aprendizagem. Os comandos "treine" e "copie" são freqüentes nos exercícios mimeografados e tarefas/deveres copiados nos cadernos. A prática docente que tem a repetição e a memorização como estratégias de ensino decorre de concepções específicas dos processos de aprendizagem. A descontextualização cultural da informação escolar à qual o aluno é submetido e a concepção da escrita enquanto mera transcrição gráfica dos sons da língua falada são identificadas por Ferreiro (1985) como premissas que norteiam condutas metodológicas predominantes no processo de alfabetização nas escolas. Sendo a escrita concebida como transcrição gráfica dos sons, justifica-se a repetição descontextualizada de sílabas para memorização. Tal princípio desconsidera, ao mesmo tempo, a língua escrita enquanto sistema de representação e o aluno como agente de construção de conhecimento que interage com a língua escrita, elaborando hipóteses sobre ela, ensaiando regras, testando possibilidades, (re)construindo-a ativa e inteligentemente. Além disso, tal conduta dissocia o decifrado (os sons lidos a partir de seus símbolos/letras) do sentido. Essa dissociação resulta de uma abordagem da leitura que leva a criança a esquecer o sentido, priorizando a compreensão mecânica da decifração dos sons.

Segundo prognóstico de Ferreiro e Teberosky (1985), alguns alunos, nesse processo de dissociação, insistirão na busca de um sentido para o texto. No entanto, uma parcela importante dos alunos não superará o divórcio inicial, permanecendo na condição de ler sem saber o significado do que foi lido.

A leitura que os alunos realizavam em sala de aula exemplifica as colocações feitas pelas autoras. Em uma situação, a Professora Regente, após escrever um texto no quadro de giz, solicitou aos alunos que fizessem a leitura. Os alunos liam cada sílaba separadamente: "ele - fol - vol - ta - volta - mu - mui - to - ca - ça - caça - cansa - do (...)"; ou: “a - taaaar - de - de - pois - de - taaaa - ter fe - i - to - muuuu - i - to - pão - ele - (o aluno hesita, a professora complementa: volta) - caaaan - sado - maaaaas - vê - eeeeeedu - a - sua - eeeees - pe - ra - e - ri - a - li - vi - a - do (...)".

Do mesmo modo como se adota a repetição de sílabas e de palavras no processo de aprendizagem, as ilustrações que as 
acompanham também são repetidas.

\section{Sujeito cognoscente e sensível, cidadão em formação}

Quanto às respostas dos alunos às atividades envolvendo desenhos reproduzidos, é necessário registrar que as crianças não são totalmente passivas a elas. Serrano (1989), ao discutir a participação dos meios audio-visuais na formação da visão de mundo das crianças, é enfático no argumento de que os meios de comunicação não representam a única via de aquisição de informações por parte da criança, "nem sequer a mais importante" (p. 60). A criança adquire novas informações por meio da observação e da exploração ativa de seu meio, do reprocessamento do conhecimento anteriormente organizado e, finalmente, através do contato com as fontes comunicacionais. As crianças processam as informações, elaborando representações de si mesmas, dos outros e de tudo o que as cerca. A informação e a forma do instrumento pela qual ela é passada não têm, em si, autonomia na atuação sobre a gênese ou a transformação de tais representações. Todas as fontes de informação às quais os alunos têm acesso são utilizadas em suas operações cognitivas.

Além disso, visões de mundo não são comunicadas apenas nos textos dos discursos ou nas composições visuais das imagens, "mas também nos contextos de interação comunicativa" (SERRANO, 1989, p. 62). Tais contextos, nos quais a comunicação se dá, reproduzem os valores dominantes, legitimando a ordem social vigente. Os processos de produção, circulação e utilização das informações transmitidas pelos meios de comunicação são explicados pelo sistema social, econômico, cultural, escolar, mais do que pelos conteúdos da informação. Nesse sentido, é importante "garantir à criança o acesso a uma comunicação que não limite, nem empobreça, nem mistifique sua possibilidade de se apropriar informativamente do que a cerca" (p. 65), mas não se deve cometer o equívoco de atribuir apenas aos meios de comunicação a responsabilidade primeira pelos moldes de construção das imagens infantis, pelos resultados nos seus projetos escolares, pelas imagens que passam a produzir.

Situando o desenho reproduzido no contexto comunicacional, as respostas das crianças às atividades com desenhos repro- 
duzidos podem ser classificadas em três grupos. No primeiro, os alunos têm uma atitude mais passiva, esforçando-se para seguir todas as instruções, buscando aprovação para os resultados; o segundo grupo de alunos estabelece uma relação mais ativa com os desenhos, alterando-lhe o traçado, não seguindo as instruções, descobrindo novas possibilidades na execução e até mesmo ignorando a atividade proposta, realizando outras experimentações; finalmente, os alunos de um grupo intermediário oscilam entre a obediência às orientações na execução dos trabalhos e a dificuldade de concentração bem como a pouca habilidade motora, o que determina alterações nos resultados. Estão nesse grupo aqueles cuja intenção inicial é alterar a proposta, mas ante a desaprovação por parte da professora, retomam as orientações originais.

Nesse sentido, as questões implícitas no uso do desenho reproduzido devem ser consideradas em sua dimensão histórico-cultural, de acordo com a concepção de ensino, do contexto no qual ele está inserido. No entanto, urge que tanto o ensino de arte, quanto a inserção da imagem no início da escolarização, sejam discutidos em profundidade, pois a qualidade das informações (incluídas as visuais) bem como dos meios de comunicação (entre eles o desenho reproduzido, as imagens impressas diversas, e outros) possibilitados aos alunos devem ser assegurados, se tivermos, de fato, em vista uma sociedade mais democrática e justa.

Para tanto, é imprescindível que a formação inicial e contínua dos professores lhes propicie a construção efetiva de conhecimento no campo das artes visuais, da linguagem visual e de seu uso no contexto educacional, superando o cenário apontado por Barbosa (1996), em que prevalecem "as imagens ruins dos livros didáticos, as imagens das folhas de colorir, e no melhor dos casos, as imagens produzidas pelas próprias crianças" (p. 12).

Destaca-se, nessa direção, a necessidade de que seja ampliado o conceito de alfabetização para uma dimensão cultural ao invés de estar limitado ao aprendizado e à repetição mecânica de letras, palavras, frases e números. Tal concepção estrita é a que abriga a imagem, o desenho como meros instrumentos a serviço dos outros conteúdos, destituídos das referências estético-artísticas. É preciso não esquecer que "não se alfabetiza fazendo apenas as crianças juntarem as letras. Há uma alfabetização cul- 


\section{Notas}

1- De acordo com a abordagem construtivista, proposta por Jean Piaget, o conhecimento não está pré-formado no sujeito, nem é totalmente determinado pelo meio ambiente. A aquisição de conhecimentos processa-se na interação da criança com o objeto a conhecer. Cf. PILLAR, (1996).

2- Segundo Piaget, as etapas do desenvolvimento cognitivo são: sensoriomotora, pré-operatória, operatório-concreta e operatório-formal. Cf. DAVIS e OLIVEIRA, (1994).

3- O "auto-ditado" é um tipo de exercício mimeografado, no qual aparecem várias figuras que os alunos devem identificar e escrever o nome correspondente numa linha abaixo. A imagem substitui a verbalização das palavras por parte do professor. As figuras são selecionadas de acordo com as palavras que estão sendo aprendidas e aquelas que o professor pretende que sejam relembradas ou reforçadas.

\section{Referências Bibliográficas}

AZEVEDO, Fernando de. A cultura brasileira. $1^{\text {a }}$ ed.: 1945. Brasília: Editora UnB/Editora UFRJ, 1996.

BARBOSA, Ana Mae T. A imagem no ensino da arte. São Paulo: Ed. Perspectiva, 1996.

BOURDIEU, Pierre. Los tres estados del capital cultural. Sociológica, México, Universidade Autonoma Metropolitana, v. 2, n. 5, p. 11 - 17, otoño/1987.

BRAGANÇA, Angiolina D. et all. Porta de papel: alfabetização - cartilha. São Paulo: FTD, 1989.

BRASIL. Regulamento para a Escola Normal. Revista Pedagógica, Rio de Janeiro, Livraria Classica de Alves, n. 3, p. 134 - 137, dez./1890.

Decreto $n^{\circ} 38$ de maio de 1893. Revista Pedagógica, Rio de Janeiro, Livraria Classica de Alves, n. 25, 26 e 27, p. 172 - 174, set./1893.

Congresso. Senado Federal. Diretrizes e bases para o ensino de $1 .^{\circ}$ e $2 .^{\circ}$ graus; histórico da lei 5.692, de 11 de agosto de 1971. Tomo I. Brasília: Senado Federal, 1971.

Congresso. Senado Federal. Lei de Diretrizes e Bases para a Educação No 9394 de 20 de dezembro de 1996. Brasília: Senado Federal, 1996.

BRZEZINSKI, Iria. A formação do professor para o início da escolarização. Goiânia: Ed. UCG/SE, 1987.

CARVALHO, Maria da A. D. O Processo silábico de alfabetização. (s.d.). Mimeo.

COMÉNIO, João Amós. Didática magna. Lisboa: Fundação Calouste Gubenkian, 1985.

DAVIS, Cláudia, e OLIVEIRA, Zilma de M. R. de. Psicologia na educação. São Paulo: Cortez, 1994. 
FERREIRA, Aurélio B. de H. Novo dicionário Aurélio da língua portuguesa. Rio de Janeiro: Ed. Nova Fronteira, 1986.

FERREIRO, Emília. Reflexões sobre alfabetização. São Paulo: Cortez, 1994.

FERREIRO, Emília; TEBEROSKY, Ana. Psicogênese da língua escrita. Porto Alegre: Artes Médicas, 1985.

FUSARI, Maria F. de R. e. Multimídias e formação de professores e alunos: por uma produção social da comunicação escolar de cultura. 1994. mimeo. OSTROWER, Fayga. Criatividade e processos de criação. Petrópolis: Vozes, 1987.

PILLAR, Analice D. Desenho e escrita como sistemas de representação. Porto Alegre: Artes Médicas, 1996a.

Desenho e construção de conhecimento na criança. Porto Alegre: Artes Médicas, 1996b.

RODRIGUES, Augusto. Função da arte na educação. Revista de Educação e Cultura, Recife, Secretaria de Educação e Cultura, n. 5, p. 64 - 66, 1960.

SALVIANO, Ana Regina M. Trajetória histórica da escola normal no Brasil e no Distrito Federal: em busca de seus fundamentos. Brasília, Faculdade de Educação, UnB, 1995. Dissertação de mestrado.

SERRANO, Manuel Martin. A participação dos meios audiovisuais na construção da visão do mundo das crianças. Tecnologia da Educação, Rio de Janeiro, $n^{\circ}$ 87/88, Rio de Janeiro, p. 58 - 65, mar./jun, 1989.

WILLIAMS, Robin. Design para quem não é designer. São Paulo: Callis, 1995.

\section{Alice de Fátima Martins}

Doutora em Sociologia (UnB); mestre em Educação (UnB); arte-educadora; coordenadora do Mestrado em Cultura Visual da Faculdade de Artes Visuais FAV/UFG. 